\title{
Ex vivo Visualization of Human Gliomas with Cross-Polarization Optical Coherence Tomography: Pilor Study
}

DOI: 10.17691/stm2016.8.4.02

ReceivedMay 16, 2016

K.S. Yashin, PhD Student, Department of Neurosurgery'; Junior Researcher,

Laboratory of High-Resolution Microscopy and Gene Technology, Institute of Biomedical Technologies2;

E.V. Gubarkova, PhD, Junior Researcher, Laboratory of Studying Optical Structure of Biotissues, Institute of Biomedical Technologies';

E.B. Kiseleva, PhD, Researcher, Laboratory of Studying Optical Structure of Biotissues, Institute of Biomedical Technologies;

S.S. Kuznetsov, MD, DSc, Professor, Department of Pathological Anatomy2;

M.M. Karabut, Junior Researcher, Laboratory of Studying Optical Structure of Biotissues, Institute of Biomedical Technologies;

L.B. Timofeeva, PhD, Assistant in the Department of Histology with Cytology and Embriology2;

L.B. Snopova, DSc, Associate Professor, Head of Morphological Department,

Central Scientific Research Laboratory2;

A.A. Moiseev, PhD, Researcher, Laboratory of High-Sensitivity Measurements ${ }^{3}$; Researcher, Laboratory of Optical Coherence Tomography, Institute of Biomedical Technologies;

I.A. Medyanik, MD, PhD, Senior Researcher, Group Microneurosurgery';

L.Ya. Kravets, MD, DSc, Professor, Chief Researcher, Group Microneurosurgery';

N.D. Gladkova, MD, DSc, Professor, Vice Director for Science, Institute of Biomedical Technologies ${ }^{2}$

${ }^{1}$ Privolzhsky Federal Research Medical Centre, Ministry of Health of the Russian Federation,

18 Verkhne-Volzhskaya naberezhnaya St., Nizhny Novgorod, 603155, Russian Federation;

${ }^{2}$ Nizhny Novgorod State Medical Academy, 10/1 Minin and Pozharsky Square, Nizhny Novgorod, 603005,

Russian Federation;

3Institute of Applied Physics, Russian Academy of Sciences, 46 Ul'yanova St., Nizhny Novgorod, 603155,

Russian Federation

Optical coherence tomography (OCT) is a promising method of optical diagnostics in neurosurgery. This paper presents the initial results of using cross-polarization OCT (CP OCT) for the visualization of glioma tissue. CP OCT can detect the scattering and polarization properties of tissues and thereby provide more information about their structure than traditional OCT.

The aim of the study was to evaluate the capabilities of CP OCT as an imaging tool for the visualization of glial tumors with different degrees of malignancy.

Materials and Methods. The study was performed on material obtained from the intraoperative biopsies (ex vivo specimens) of 18 patients with gliomas ranging from Grade I to Grade IV. Seventy nine samples of tumor and non-tumor tissue were studied using the CP OCT device developed the Institute of Applied Physics of the Russian Academy of Sciences (Nizhny Novgorod, Russia). 361 CP OCT images were acquired and analyzed. They were compared with histological data seen in sections coincident with the planes of the OCT scans.

Results. The correspondence between the CP OCT images of human brain tissue and glial tumors and their morphological features was determined. A comparative evaluation of the characteristics of the CP OCT signals of glial tumors Grade I-IV and non-cancerous brain tissue was carried out.

Conclusion. The morphological features of white matter and glial tumors can be differentiated based on the intensity, homogeneity and attenuation of the CP OCT signals. The use of high-speed spectral CP OCT device appears to have great potential in the neurosurgery practice.

Key words: cross-polarization optical coherence tomography; CP OCT; brain; glioma; astrocytoma; glioblastoma.

Optical coherence tomography (OCT) is a newly emerging technology for obtaining two- and threedimensional images of tissue structures in real-time and with micron resolution at depths of 1-2 $\mathrm{mm}$. The technology is based on low-coherence interferometry in the near IR range of wavelengths $(700-1,300 \mathrm{~nm})$. The resulting images are formed on the basis of a coherence analysis of the field of the backscattering of the probing wave, and characterization of the extent of the scattering caused by the optical heterogeneities of the tissue that

For contacts: Konstantin S. Yashin, e-mail: jashinmed@gmail.com 
are the result of the composition and structure of the structures within it $[1,2]$. The potential clinical use of OCT imaging in diagnosing the pathology of different organs, including the retina, gastrointestinal tract, coronary vessels, breast, skin and brain has been widely studied [3-6]. There has recently been greatly increased interest in the use of OCT as a method of intraoperative diagnostics in the surgery of glial brain tumors [7-9]. Glial tumors develop from the cells of the white matter of the brain and are characterized by infiltrative growth. The importance of determining the boundaries of the tumor growth and the required extent of total glioma excision is due to the significant association between the size of tumor resection and the survival [10-12]. A number of ex vivo and in vivo studies have shown the capacity of OCT for differentiating the boundaries of tumor growth through qualitative and quantitative evaluation of the signals obtained [7-9, 13].

Various technologies have been developed to apply intraoperative OCT in clinical practice, for example, adding OCT as a feature of the microscopes used for microneurosurgery [14-16]. It is noteworthy that, in traditional OCT images, brain tissue appears structureless. Polarization modifications can make the method more informative: they record the effects of the changing plane of light polarization as it passes through the tissue that are caused by interaction with anisotropic structures within the sample. Polarization-sensitive OCT (PS OCT) based on the birefringence of the medium can differentiate tissue elements which are poorly visualized or do not show up at all in traditional OCT images. These are mainly structures that have longitudinal dimensions, much larger their transverse ones, such as collagen and muscle fibers [17-19]. We have also demonstrated that PS OCT and polarization-sensitive optical coherence microscopy can visualize myelinated nerve fibers and their orientation in the white matter tracts [20, 21]. The current work is the first to use PS OCT - crosspolarization OCT (CP OCT) to investigate the human brain; however, we have previously used it to evaluate a range of other human tissues [22-24].

Materials and Methods. The study was performed on material from operative biopsies (ex vivo specimens) from 18 patients with glial tumors of different malignancy grades: Grade I -2 patients, Grade II -3 , Grade III -3 , and Grade IV - 10 patients (See the Table, Figure 1 (a)). Access to the neoplasms was performed using frameless neuronavigation and intraoperative neuromonitoring, while taking into account the locations of adjacent functionally important areas of the brain. Each tumor was excised using microsurgical technique under an operating microscope. In the region of access to the focus of the tumor the perifocal tumor zone (edge of the tumor resection) (Figure 1 (b); green dotted line in the MRI image) subject to coagulation was accurately marked and removed with tumor pincers. During the tumor excision specimens were taken from the center and periphery of the tumor (Figure 1 (b); areas of red and purple dotted lines respectively in the MRI image). The biopsy material was placed on pads moistened with saline solution and sent for imaging within $2 \mathrm{~h}$. In the post-operative period no patient demonstrated any increased functional deficit.

\section{Characteristics of patients}

\begin{tabular}{|c|c|c|c|c|c|}
\hline No. & Grade & $\begin{array}{l}\text { Age } \\
\text { (years) }\end{array}$ & Gender & $\begin{array}{c}\text { Localization (lobe): } \\
\text { frontal }-1, \text { parietal }-2 \text {, } \\
\text { temporal }-3, \text { two or more }-4 \text {, } \\
\text { cerebellum }-5\end{array}$ & $\begin{array}{l}\text { Hemisphere: } \\
\text { right }-1 \text {, left }-2 \text {, } \\
\text { both }-3\end{array}$ \\
\hline 1 & 1 & 51 & Male & 2 & 1 \\
\hline 2 & I & 18 & Male & 1 & 1 \\
\hline 3 & ॥ & 49 & Female & 1 & 2 \\
\hline 4 & II & 53 & Male & 1 & 3 \\
\hline 5 & II & 43 & Female & 4 & 2 \\
\hline 6 & III & 60 & Female & 3 & 2 \\
\hline 7 & III & 65 & Female & 3 & 2 \\
\hline 8 & III & 26 & Female & 4 & 2 \\
\hline 9 & IV & 76 & Female & 4 & 2 \\
\hline 10 & IV & 59 & Male & 3 & 1 \\
\hline 11 & IV & 58 & Male & 4 & 2 \\
\hline 12 & IV & 65 & Female & 1 & 1 \\
\hline 13 & IV & 75 & Female & 4 & 2 \\
\hline 14 & IV & 63 & Male & 2 & 3 \\
\hline 15 & IV & 41 & Female & 5 & - \\
\hline 16 & IV & 54 & Female & 2 & 1 \\
\hline 17 & IV & 51 & Female & 4 & 2 \\
\hline 18 & IV & 52 & Male & 3 & 1 \\
\hline
\end{tabular}



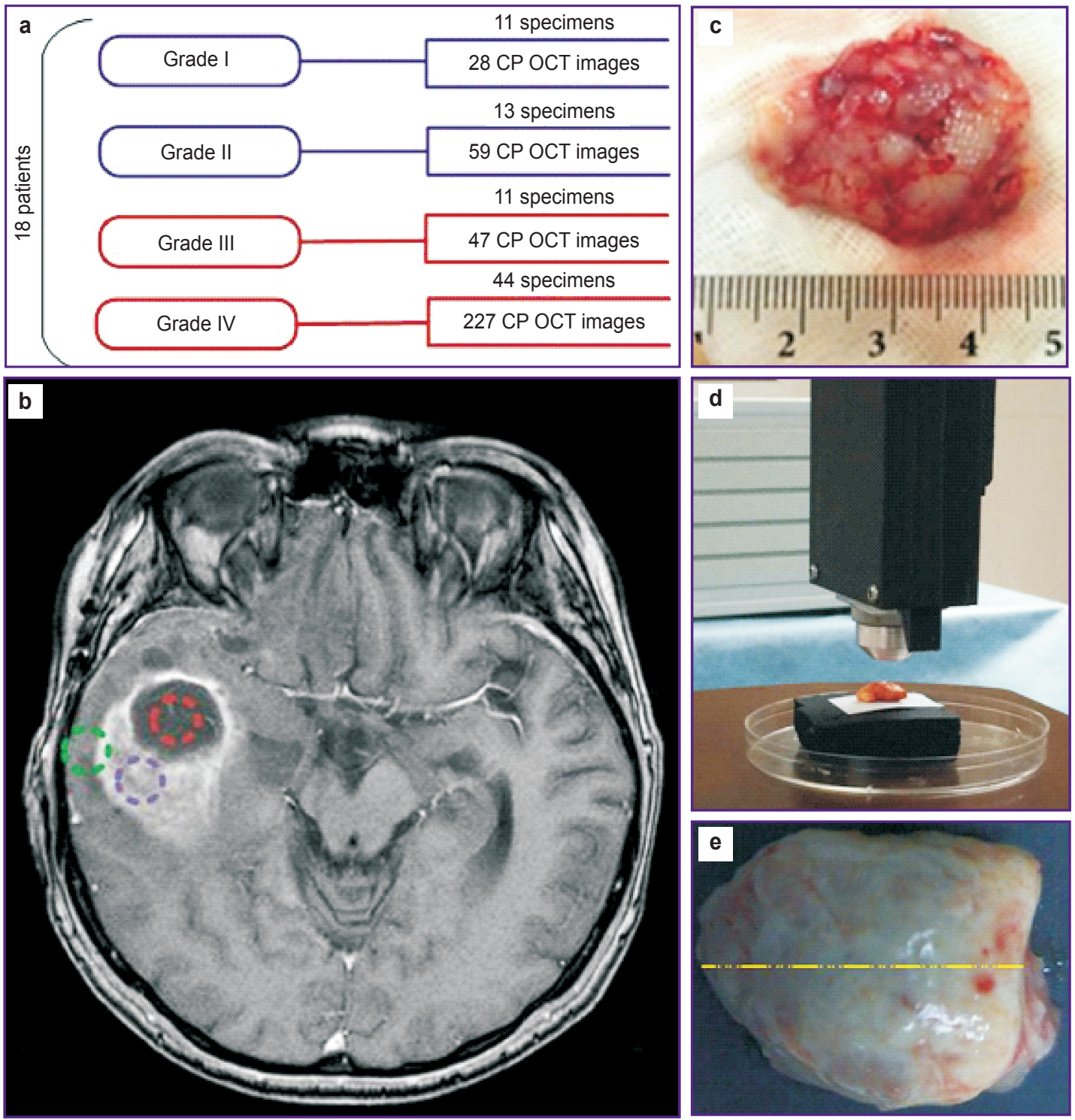

Figure 1. Design of the CP OCT study: (a) the study was performed on material from operative biopsies from 18 patients with glial brain tumors of different grades of malignancy; in total we analyzed 79 specimens and obtained 361 CP OCT images; (b) MRI image of a patient's brain with glioblastoma of the right parietal-temporal region with schematic marking of the areas of operative biopsies: area within the red dotted line - center of tumor; area within purple dotted line - periphery of the tumor; area within green dotted line - edge of the resection, perifocal zone (at the place of access); (c) specimen of the excised brain tumor sent for investigation (within $2 \mathrm{~h}$ ) in a pad moistened with saline solution; (d) position of contactless front optic fiber probe for CP OCT investigation of tissue; (e) schematic marking of scanning area of the specimen along the central line of the tumor (yellow dotted line)

We obtained permission from the Ethical Committee of the Privolzhsky Federal Research Medical Centre of the Ministry of Health of the Russian Federation for experimental studies on the ex vivo human specimens.

Cross-polarization OCT. The studies were performed on a high-speed OCT device that uses the principle of spectral signal reception developed in the Institute of Applied Physics of the Russian Academy of Sciences (Nizhny Novgorod, Russia) [25, 26]. The optical design of the high-speed variant of the OCT device uses a system with a common optical path for both the reference and signal waves but has two channels for signal detection: one recording the backscattered light that has preserved its initial state of polarization (co-polarization) after backscattering within the tissue, and the other that determines any orthogonal polarization (cross-polarization). Thus, the resulting CP OCT image includes an upper part co-polarization and a lower part - cross-polarization (Figure 2 (a), (d), (g), (j), (m)). The CP OCT device with a working wavelength of $1,310 \mathrm{~nm}$ has the following 

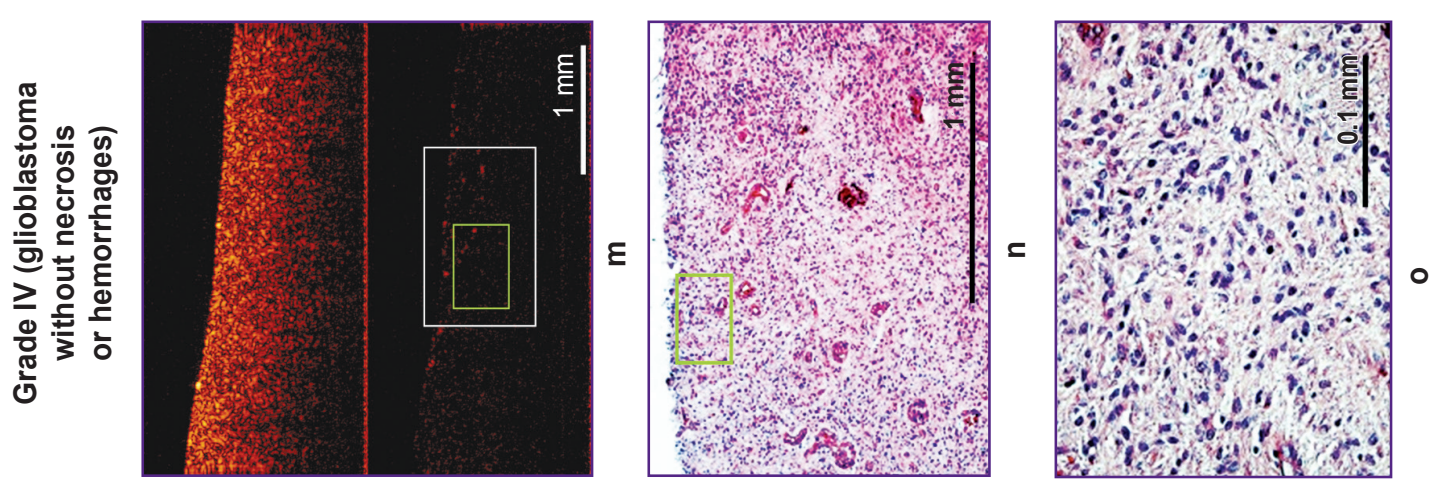

芦 음. 트 음 원 흔

ธั่ ๖े 헝 흐 Ф $\mid$

흘 응 은

ह Nㅗㅇ

पำ

ه
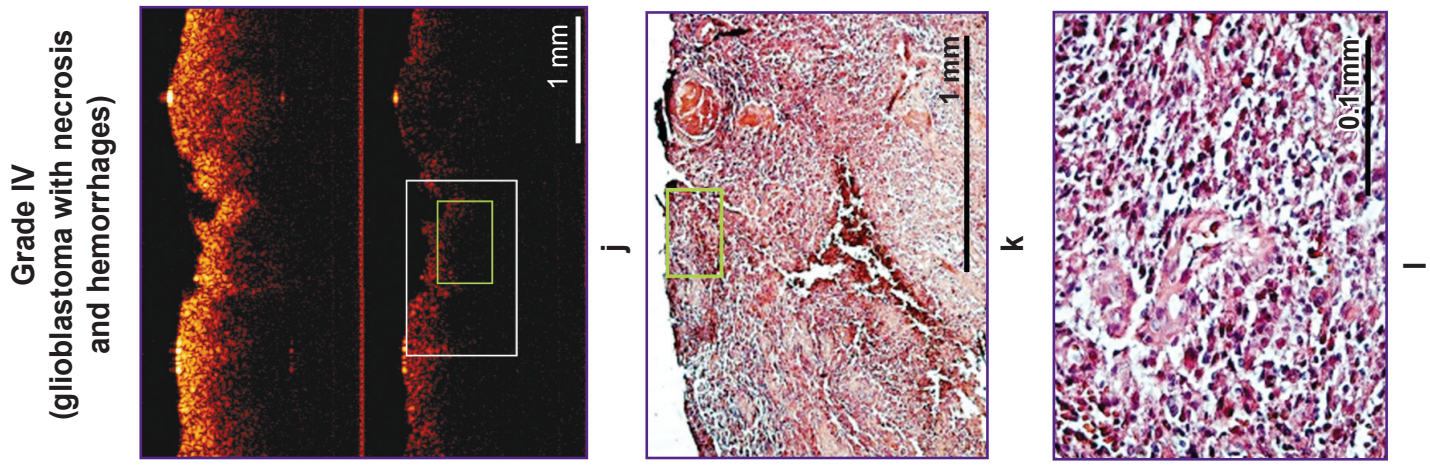

वृ की

๑ 닌 응

$\pm . \frac{1}{\mathrm{c}}$

勿

䒕

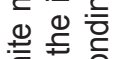

专

츤 는 잉

을 ญ
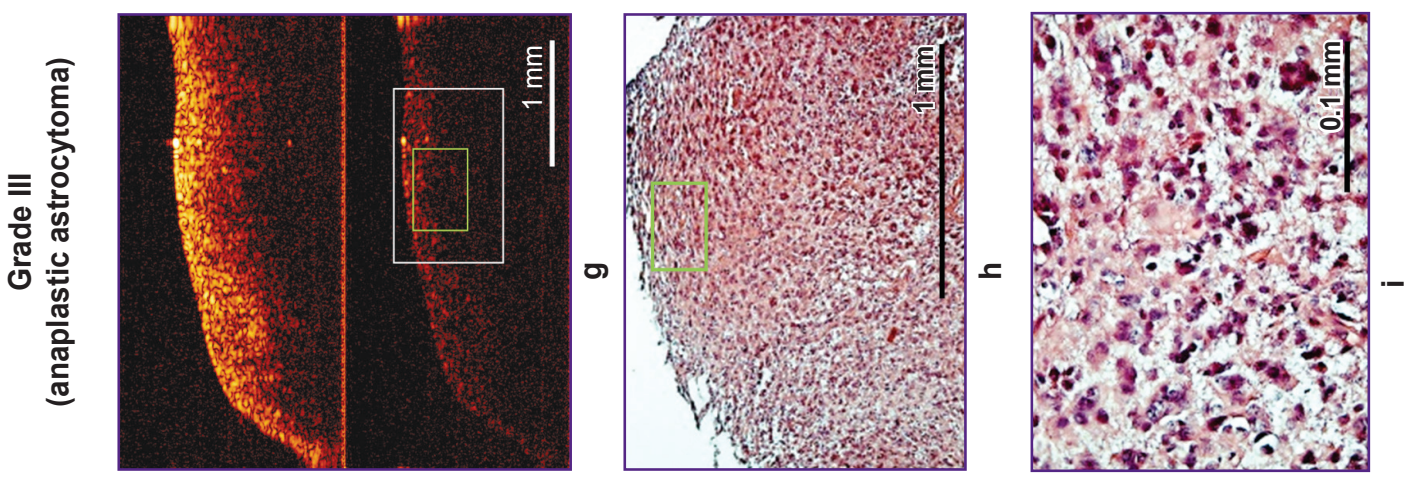

은 윽 님

둥 듬

ह ํㅠㄴ 전

은 증

일 ญ

ल음

든 Ð

으

으 으

শ
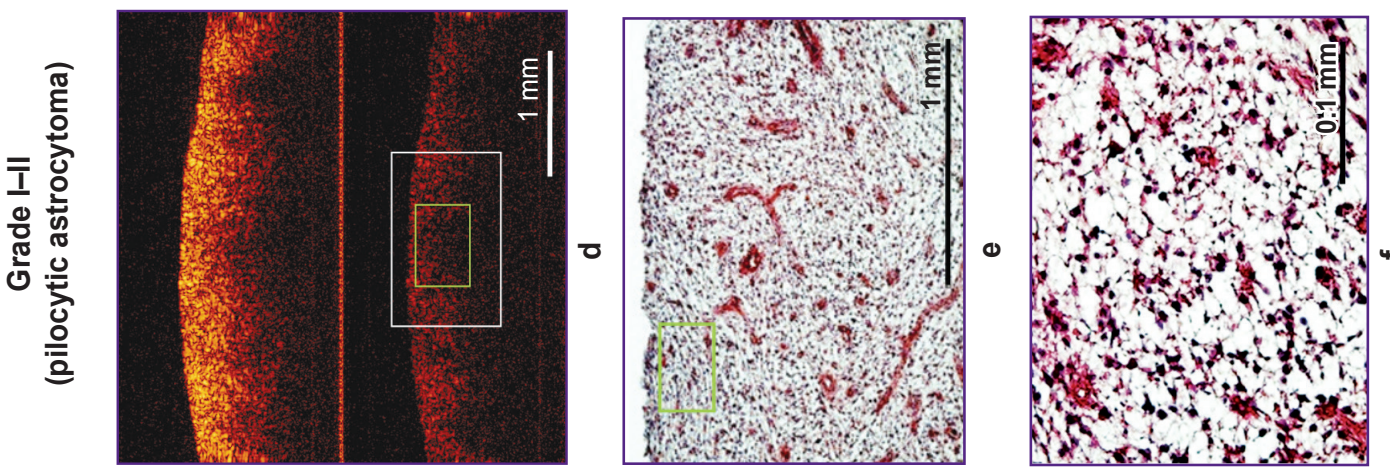

论 呈

ฮิ ฮ

है

ত্তে क्ठ 즈

응 흐음

零苛

응 궁ㅇ

등 음
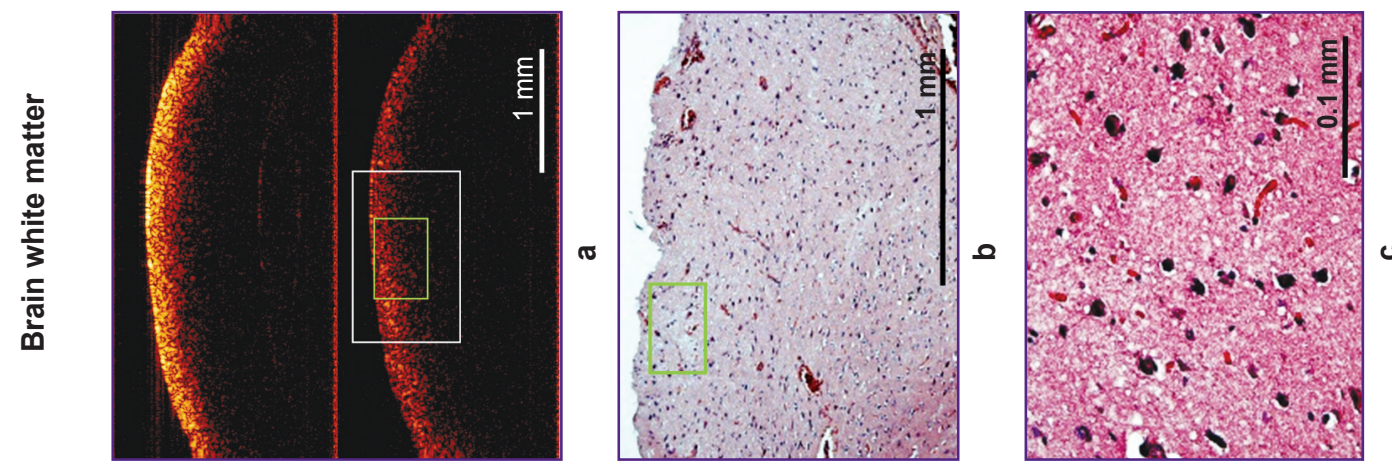

के 흥 등 등

늘 융 व

0

웡

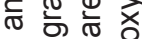

比䒕| 豞

O

ง

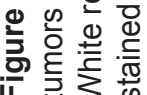


features: radiation power at the object $\sim 20 \mathrm{~mW}$, depth resolution in air $\sim 10 \mu \mathrm{m}$, transverse resolution $\sim 15 \mu \mathrm{m}$, depth of scanning in air $\sim 1.7 \mathrm{~mm}$, rate of scanning 20,000 A-scans/s, frequency of obtaining B-scans for each pair of images with a size of $4 \times 2 \mathrm{~mm}-40$ shots/s. A more detailed description of the system including the optical layout and the method of obtaining crosspolarization images has been published previously $[24,26,27]$. The high-speed spectral CP OCT device is equipped with an optic fiber probe with an external diameter of $8 \mathrm{~mm}$ and which has a contactless connection with the surface of the tissue under study (Figure $1(\mathrm{e})$ ). We analyzed 79 specimens and obtained 361 CP OCT images in total (See Figure 1 (a)).

It is noteworthy that the CP OCT device described in this work is appropriate for use in clinical practice. Firstly, the imaging system is compact, has a fiber system for signal transmission to the object; can be used in operating rooms and integrated into the operating microscope; secondly, the system that has been developed forms and displays CP OCT images in real-time. This is especially important for clinical intraoperative use.

Histological study. After obtaining CP OCT images of the nervous tissue we marked the area of scanning on the specimen with histological ink, then we fixed the specimen in $10 \%$ formalin for $48 \mathrm{~h}$ and made a series of histological sections through the marked area. Thus, the plane of CP OCT scanning coincided equidistantly with the plane of the histological sections. The series of sections were stained with hematoxylin and eosin and were observed in transmitted light with a Leica DM2500 (Leica Microsystems, Germany) microscope, equipped with a DFC $245 \mathrm{C}$ digital camera.

For each of the histological sections we recorded the characteristics of the tissue structure, grouping them as follows: group 1 - edge of tumor resection (brain white matter); group 2 - gliomas with low malignancy grade (Grades I-II); group 3 - anaplastic astrocytoma (Grade III); group 4 - glioblastoma with foci of necrosis (Grade IV) and group 5 - glioblastoma without necrotic foci (Grade IV).

Results and Discussion. Unchanged tissues and brain tumors are characterized by considerably different optical properties: different degrees of absorption and light scattering within the tissues, as well as a variety of polarization properties [28]. Considerable changes in cell structures are typical of any tumor tissue, for example, nuclear polymorphism and an increased nuclearcytoplasmic correlation [29]. All these factors change the scattering characteristics of the tissue [28]. Obviously, in the case of glial brain tumors the specific features of OCT signal formation are mediated by two factors [9]: 1) the increase in cell density and the increase in nuclearcytoplasmic correlation both contribute to the increased scattering properties of the tissue; 2 ) degradation of the myelin of the brain white matter as a result of infiltrative tumor growth causes a reduced level of light scattering in the tissue. The latter statement is based in investigations showing that the infiltrative growth of tumor cells destroys the structure of the myelin and reduces its formation [30-32].

This work is the first time that changes in the spatial and structural organization of fibrous structures (including myelinated nervous fibers) in glial brain tumors have been studied using CP OCT. By combing cross-polarization images with traditional ones we can record the effects of the changing plane of light polarization (birefringence and cross-scattering) while it passes through the tissue, as a result of its interaction with anisotropic structures in the specimen.

Ex vivo analysis of white matter specimens at the edge of the tumor resection showed that the CP OCT images in co- and cross-polarizations (Figure 2 (a); the upper and the lower parts of the image, respectively) contain stripes showing a high-level OCT signal at the surface but a regular reduction in it with depth. Signal decay can be observed at a depth of 250-300 $\mu \mathrm{m}$. In this region the white matter does not undergo serious morphological changes (other than tissue edema) and is characterized by a regular and dense arrangement of myelinated nerve fibers and glial cells (Figure 2 (b), (c)). This explains the presence of a high-intensity homogeneous but rapidly decaying OCT signal in both co- and cross-polarization. The presence of an intense homogeneous OCT signal in both co- and crosspolarizations indicates the capacity of the unchanged nervous tissues for cross-scattering.

Low malignancy gliomas (Grades I-II) have an astrocytic origin, their poor infiltrative growth being accompanied by only minor damage to the microarchitectonics of the surrounding white matter. These tumors are characterized by a moderate increase in the density of tumor astrocytes (Figure 2 (e), (f)) [33]. The corresponding CP OCT image has a higher, but less intense and more heterogeneous backscattering signal compared to the white matter, showing a slow irregular decay on average at a depth of about $500-600 \mu \mathrm{m}$ (See Figure 2 (d)). The heterogeneity of the signal is caused by the structural disorganization of the tissue with complete or partial destruction, or stratification, of the neuropil elements (clusters of nerve cell processes), the chaotic arrangement of the tumor cells with enlarged hyper-chromatic nuclei of irregular shape, or the presence of cysts and calcifications in a number of cases. In histological investigations some low malignancy gliomas may contain myelinated axons [33], but as tumor growth progresses the myelin is degraded. In our view it is this that reduces the signal intensity in co- and cross-polarization and contributes to its heterogeneity compared to the unchanged white matter. Evidently, the signal in crosspolarization appears to be due to cross-scattering by the multiple cell processes forming the tumor matrix (Figure 2 (d); lower part of the image). This correlates with the notion of a "fibrillar" structure to the diffuse astrocytomas (including glioblastomas), the matrix of which is formed by tumor cell processes [33]. That the tumor cells are 
loosely arranged is mainly connected with the presence of perivascular and pericellular edema, so the OCT signal is characterized by a low decay rate in both co- and crosspolarization. The severity of the edema has a considerable impact on the scattering properties of the brain tissue: with increased edema the coefficient of scattering falls [34], and this is reflected in the CP OCT images as a reduction in intensity and the rate of signal decay.

Anaplastic astrocytoma (Grade III) represents high malignancy tumors and is characterized by an increase in the number of tumor cells with a high degree of nuclear atypia and polymorphism (Figure 2 (h), (i)). Although the spatial resolution of OCT does not allow direct identification such signs, this explains the presence of distinct differences between the OCT signals in the images of pilocytic astrocytoma (Grades I-II) and those from anaplastic astrocytoma (Grade III) enabling us to retain the same CP OCT criteria for differential diagnostics to separate the unchanged white matter at the edge of the tumor resection for each form of astrocytoma, the criteria for which were formulated for Grades I-II. We hope that the quantitative analysis of images which will be used in our further studies will allow identification of these differential features.

Glioblastoma (Grade IV) is the most malignant of all astrocytic tumors. Along with the features typical of anaplastic astrocytomas this type exhibits such specific histopathological properties as microvascular proliferation and areas of hemorrhaging and necrosis (Figure 2 (k)). The specific pathomorphological feature of the glioblastoma is its pseudo palisades - clusters of tumor cells around the necrotic center [35]. These structural peculiarities of the tumor generate specific indications of the glioblastoma in the CP OCT image (See Figure 2 (j)). The CP OCT signal has an explicit heterogeneity with alternating areas of high and low intensity, caused respectively by the areas of high cellular density and of necrotic changes (Figure 2 (I)). The explicit heterogeneity of the OCT signal decay with depth (along the transverse axis) should also be noted, as it may indicate differing densities in the arrangement of the structural elements in the tissue and the severity of the edema. In areas of severe edema the signal decays more slowly, while in regions of more minor edema the decay is faster.

A number of glioblastomas have a structure similar to that of anaplastic astrocytoma with high cellular density against a background of severe edema but with no necrotic foci or hemorrhages (Figure 2 (n), (o)). These forms were analyzed separately. The corresponding CP OCT images in co-polarization in these cases were characterized by a uniform change in the backscattering signal with depth and a hardly noticeable signal in crosspolarization (Figure $2(\mathrm{~m})$; the upper and lower parts of the image, respectively). The low level of the signal in cross-polarization is likely to be connected with the absence of orderly fibrous structures. In the works of other authors, similar morphological types of glioblastoma have not been considered.
Currently the main OCT criterion for differential diagnostics to distinguish the unchanged white matter from astrocytomas is based on a visual evaluation of the heterogeneity signal of back scattering in the OCT images [7, 8]. Our analysis with CP OCT enabled us to conclude that the character of the decay of the OCT signal is also informative. The ability to analyze the signal level in cross-polarization considerably increased the effectiveness of the method. We determined a clear regularity - the unchanged white matter is characterized by a high signal level in cross-polarization; while, for any diffuse astrocytoma, a low signal level of cross-scattering is a specific feature.

When comparing CP OCT images of astrocytomas against increasing grade of malignancy (Grade I $\rightarrow$ Grade IV) there is a trend toward increased signal heterogeneity in both polarizations but a decreased signal level in cross-polarization. The reason is perhaps an increase in cellular density and a displacement towards increased fibrous and cellular tumor components in those tumors classed as having higher grades of malignancy.

Further development of the application of OCT will be through advances in the methods of quantitative processing of the signals. The most informative approach in this regard will be determination of the coefficients of scattering by the unchanged brain tissue and by the tumor $[8,9]$. This is the field of further investigations being undertaken by our team.

Conclusion. The histological features of white matter and of gliomas of different grades of malignancy can be differentiated in CP OCT images according to characteristics of their OCT signal such as intensity, homogeneity and the dynamics of signal decay in co- and cross-polarization.

The spatial resolution of OCT (about $10 \mu \mathrm{m}$ depth wise and $15 \mu \mathrm{m}$ along the transverse axis) is sufficient to differentiate diagnostically relevant changes in the microstructure of brain tissue: the different density/ correlation between cellular and fibrous structures in the tissue, the presence of necrosis and hemorrhages as well as the presence of myelinated fibers in the tissue. High heterogeneity along the transverse axis of the OCT signal or its complete absence in cross-polarization is a direct indicator of highly malignant glioblastomas.

Thus, CP OCT is considered to be a promising method of intraoperative diagnostics in neurosurgery that could, in real-time, significantly enhance a neurosurgeon's knowledge about the specific structural features of a tumor to be excised.

Study Funding. The work was supported by grant No.16-15-10391 from the Russian Scientific Foundation. We used a high-speed spectral CP OCT device developed and constructed under a grant from the Government of the Russian Federation, Ministry of Education and Science of the Russian Federation, Agreement No.14. B25.31.0015, RFBR No.16-32-60178 mol_a_dk.

Conflicts of Interest. The authors declare no conflicts of interest. 


\section{References}

1. Huang D., Swanson E.A., Lin C.P., Schuman J.S., Stinson W.G., Chang W., Hee M.R., Flotte T., Gregory K., Puliafito C.A., Fujimoto J.G. Optical coherence tomography. Science 1991; 254(5035): 1178-1181, https://doi.org/10.1126/ science.1957169.

2. Fercher A.F., Hitzenberger C.K., Kamp G., El-Zaiat S.Y. Measurement of intraocular distances by backscattering spectral interferometry. Optics Communications 1995; 117(12): 43-48, https://doi.org/10.1016/0030-4018(95)00119-s.

3. Su M.I., Chen C.Y., Yeh H.I., Wang K.T. Concise review of optical coherence tomography in clinical practice. Acta Cardiol Sin 2016; 32(4): 381-386.

4. Osiac E., Bălşeanu T.A., Cătălin B., Mogoantă L., Gheonea C., Dinescu S.N., Albu C.V., Cotoi B.V., Tica O.S., Sfredel V. Optical coherence tomography as a promising imaging tool for brain investigations. Rom J Morphol Embryol 2014; 55(2 Suppl): 507-512.

5. Murthy R.K., Haji S., Sambhav K., Grover S., Chalam K.V. Clinical applications of spectral domain optical coherence tomography in retinal diseases. Biomed $J$ 2016; 39(2): 107-120, https://doi.org/10.1016/j.bj.2016.04.003.

6. Zhang Y., Chen Y., Yu Y., Xue X., Tuchin V.V., Zhu D. Visible and near-infrared spectroscopy for distinguishing malignant tumor tissue from benign tumor and normal breast tissues in vitro. J Biomed Opt 2013; 18(7): 077003, https://doi. org/10.1117/1.jbo.18.7.077003.

7. Böhringer H.J., Boller D., Leppert J., Knopp U., Lankenau E., Reusche E., Hüttmann G., Giese A. Time-domain and spectral-domain optical coherence tomography in the analysis of brain tumor tissue. Lasers Surg Med 2006; 38(6): 588-597, https://doi.org/10.1002/lsm.20353.

8. Böhringer H.J., Lankenau E., Stellmacher F., Reusche E., Hüttmann G., Giese A. Imaging of human brain tumor tissue by near-infrared laser coherence tomography. Acta Neurochir (Wien) 2009; 151(5): 507-517, https://doi. org/10.1007/s00701-009-0248-y.

9. Kut C., Chaichana K.L., Xi J., Raza S.M., Ye X., McVeigh E.R., Rodriguez F.J., Quiñones-Hinojosa A., Li X. Detection of human brain cancer infiltration ex vivo and in vivo using quantitative optical coherence tomography. Science Translational Medicine 2015; 7: 292ra100, https://doi. org/10.1126/scitranslmed.3010611.

10. Sanai N., Berger M.S. Glioma extent of resection and its impact on patient outcome. Neurosurgery 2008; 62(4): 753764, https://doi.org/10.1227/01.neu.0000318159.21731.cf.

11. Sanai N., Polley M.Y., McDermott M.W., Parsa A.T., Berger M.S. An extent of resection threshold for newly diagnosed glioblastomas. J Neurosurg 2011; 115(1): 3-8, https://doi.org/10.3171/2011.2.jns10998.

12. Anokhina Yu.E., Gaidar B.V., Martynov B.V., Svistov D.V., Papayan G.V., Grigorievsky D.I. Prognostic significance of surgery volume under fluorescent intraoperative diagnostic applications in patients with malignant brain gliomas. Vestnik rossiyskoy voennomeditsinskoy akademii 2014; 1(45): 19-24.

13. Bizheva K., Unterhuber A., Hermann B., Povazay B., Sattmann H., Fercher A.F., Drexler W., Preusser M., Budka H., Stingl A., Le T. Imaging ex vivo healthy and pathological human brain tissue with ultra-high-resolution optical coherence tomography. J Biomed Opt 2005; 10(1): 11006, https://doi. org/10.1117/1.1851513.
14. Kantelhardt S.R., Finke M., Schweikard A., Giese A. Evaluation of a completely robotized neurosurgical operating microscope. Neurosurgery 2013; 72: A19-A26, https://doi. org/10.1227/NEU.0b013e31827235f8.

15. Finke M., Kantelhardt S., Schlaefer A., Bruder R., Lankenau E., Giese A., Schweikard A. Automatic scanning of large tissue areas in neurosurgery using optical coherence tomography. Int J Med Robot 2012; 8(3): 327-336, https://doi. org/10.1002/rcs.1425.

16. Lankenau E., Klinger D., Winter C., Malik A., Müller H.H., Oelckers S., Pau H.-W., Just T., Hüttmann G. Combining optical coherence tomography (OCT) with an operating microscope. In: Advances in medical engineering. Vol. 114. Springer Berlin Heidelberg; 2007; p. 343-348, https:// doi.org/10.1007/978-3-540-68764-1_57.

17. Nakaji H., Kouyama N., Muragaki Y., Kawakami Y., Iseki $\mathrm{H}$. Localization of nerve fiber bundles by polarizationsensitive optical coherence tomography. $J$ Neurosci Methods 2008; 174(1): 82-90, https://doi.org/10.1016/j. jneumeth.2008.07.004.

18. de Boer J.F., Srinivas S.M., Park B.H., Pham T.H., Zhongping C., Milner T.E., Nelson J.S. Polarization effects in optical coherence tomography of various biological tissues. IEEE J Sel Top Quantum Electron 1999; 5(4): 1200-1204, https://doi.org/10.1109/2944.796347.

19. Kuranov R., Sapozhnikova V., Turchin I., Zagainova E., Gelikonov V., Kamensky V., Snopova L., Prodanetz N. Complementary use of cross-polarization and standard OCT for differential diagnosis of pathological tissues. Opt Express 2002; 10(15): 707-713, https://doi.org/10.1364/oe.10.000707.

20. Chen W., Wang D., Du X., He Y., Chen S., Shao Q., Ma C., Huang B., Chen A., Zhao P., Qu X., Li X. Glioma cells escaped from cytotoxicity of temozolomide and vincristine by communicating with human astrocytes. Med Oncol 2015; 32(3): 43, https://doi.org/10.1007/s12032-015-0487-0.

21. Wang H., Akkin T., Magnain C., Wang R., Dubb J., Kostis W.J., Yaseen M.A., Cramer A., Sakadžić S., Boas D. Polarization sensitive optical coherence microscopy for brain imaging. Opt Lett 2016; 41(10): 2213-2216, https://doi. org/10.1364/ol.41.002213.

22. Gladkova N., Kiseleva E., Robakidze N., Balalaeva I., Karabut M., Gubarkova E., Feldchtein F. Evaluation of oral mucosa collagen condition with cross-polarization optical coherence tomography. J Biophotonics 2013; 6(4): 321-329, https://doi.org/10.1002/jbio.201200059.

23. Gladkova N., Kiseleva E., Streltsova O., Prodanets N., Snopova L., Karabut M., Gubarkova E., Zagaynova E. Combined use of fluorescence cystoscopy and crosspolarization OCT for diagnosis of bladder cancer and correlation with immunohistochemical markers. J Biophotonics 2013; 6(9): 687-698, https://doi.org/10.1002/jbio.201200105.

24. Gubarkova E.V., Dudenkova V.V., Feldchtein F.I., Timofeeva L.B., Kiseleva E.B., Kuznetsov S.S., Shakhov B.E., Moiseev A.A., Gelikonov V.M., Gelikonov G.V., Vitkin A., Gladkova N.D. Multi-modal optical imaging characterization of atherosclerotic plaques. J Biophotonics 2015, https://doi. org/10.1002/jbio.201500223.

25. Gelikonov V.M., Gelikonov G.V., Shilyagin P.A. Linear-wavenumber spectrometer for high-speed spectraldomain optical coherence tomography. Optics and Spectroscopy 2009; 106(3): 459-465, https://doi.org/10.1134/ s0030400x09030242.

26. Moiseev A.A., Gelikonov G.V., Terpelov D.A., 
Shilyagin P.A., Gelikonov V.M. Noniterative method of reconstruction optical coherence tomography images with improved lateral resolution in semitransparent media. Laser Physics Letters 2013; 10(12): 125601, https://doi. org/10.1088/1612-2011/10/12/125601.

27. Yashin K.S., Karabut M.M., Fedoseeva V.V., Khalansky A.S., Matveev L.A., Elagin V.V., Kuznetsov S.S., Kiseleva E.B., Kravets L.Y., Medyanik I.A., Gladkova N.D. Multimodal optical coherence tomography in visualization of brain tissue structure at glioblastoma (experimental study). Sovremennye tehnologii v medicine 2016; 8(1): 73-81, https:// doi.org/10.17691/stm2016.8.1.10.

28. Tuchin V.V. Lazery $i$ volokonnaya optika $v$ biomeditsinskikh issledovaniyakh [Lasers and fiber optics in biomedical research]. Moscow: FIZMALIT; 2010; 488 p.

29. Angiogenesis. In: Brain tumor pathology: current diagnostic hotspots and pitfalls. Springer Netherlands; 2006; p. 189-198, https://doi.org/10.1007/1-4020-3998-0_15.

30. Bevilacqua F., Piguet D., Marquet P., Gross J.D., Tromberg B.J., Depeursinge C. In vivo local determination of tissue optical properties: applications to human brain. Appl Opt 1999; 38(22): 4939-4950, https://doi.org/10.1364/ ao.38.004939.
31. Amberger V.R., Hensel T., Ogata N., Schwab M.E. Spreading and migration of human glioma and rat $\mathrm{C} 6$ cells on central nervous system myelin in vitro is correlated with tumor malignancy and involves a metalloproteolytic activity. Cancer Res 1998; 58(1): 149-158.

32. Alaminos M., Dávalos V., Ropero S., Setién F., Paz M.F., Herranz M., Fraga M.F., Mora J., Cheung N.K., Gerald W.L., Esteller M. EMP3, a myelin-related gene located in the critical 19q13.3 region, is epigenetically silenced and exhibits features of a candidate tumor suppressor in glioma and neuroblastoma. Cancer Res 2005; 65(7): 2565-2571, https://doi.org/10.1158/0008-5472.can-04-4283.

33. Brat D.J., Perry A. Astrocytic and oligodendroglial tumor. In: Practical surgical neuropathology. New York: Churchill Livingstone; 2010; p. 63-102, https://doi.org/10.1016/ b978-0-443-06982-6.00005-5.

34. Rodriguez C.L., Szu J.I., Eberle M.M., Wang Y., Hsu M.S., Binder D.K., Park B.H. Decreased light attenuation in cerebral cortex during cerebral edema detected using optical coherence tomography. Neurophotonics 2014; 1(2): 025004, https://doi.org/10.1117/1.NPh.1.2.025004.

35. Miller C.R., Perry A. Glioblastoma. Arch Pathol Lab Med 2007; 131(3): 397-406. 